\title{
Implementasi Kebijakan Peraturan Kepala Badan Pengawasan Keuangan dan Pembangunan Republik Indonesia Nomor 6 Tahun 2015
}

\author{
Implementation of Regulatory Policies of the Head of the \\ Indonesian Financial and Development Supervisory Agency \\ Number 6 of 2015 \\ Muhammad Hakim ${ }^{1)}$, Heri Kusmanto') \& Isnaini' ${ }^{3)}$
}

1) Pasca Sarjana Magister Ilmu Administrasi Publik Universitas Medan Area, Indonesia

2) Departemen Ilmu Politik, Fakultas Ilmu Sosial dan Ilmu Politik,

Universitas Sumatera Utara, Indonesia

3) Fakultas Hukum, Universitas Medan Area, Indonesia

\begin{abstract}
Abstrak
Tujuan dari penelitian adalah Mengetahui dan menganalisis Implementasi faktor-faktor yang menjadi hambatan dalam Impelementasi Perka BPKP RI Nomor 6 Tahun 2015 Di Inspektorat Kabupaten Aceh Tamiang. Bentuk penelitian ini adalah Kualitatif Deskriptif, Data yang digunakan dalam penelitian ini adalah data primer dan data skunder. Data Primer yang pada umumnya digunakan dalam penelitian kualitatif meliputi: Wawancara, Observasi dan Dokumentasi. Sedangkan data skunder merupakan data yang diperoleh dari literatur dan dokumen. Berdasarkan uraian hasil penelitian dan pembahasan maka ditarik kesimpulan mengenai Implementasi Perka BPKP RI Nomor 6 Tahun 2015 Tentang Grand Design Peningkatan Kapabilitas APIP di Inspektorat Kabupaten Aceh Tamiang berdasarkan teori Edward III sudah berjalan dengan baik namun belum maksimal dilaksanakan.

Kata Kunci: Inspektorat Kabupaten, Pengawasan, Implementasi, Kebijakan, Kapabilitas.
\end{abstract}

\begin{abstract}
The purpose of this research is to find out and analyze the Implementation of the factors that become obstacles in the implementation of Perka BPKP RI No. 6 of 2015 in the Inspectorate of Aceh Tamiang Regency. The form of this research is descriptive qualitative, the data used in this study are primary data and secondary data. Primary data that are generally used in qualitative research include: Interviews, Observation and Documentation. While secondary data is data obtained from literature and documents. Based on the description of the results of research and discussion, conclusions are drawn regarding the Implementation of Perka BPKP RI No. 6 of 2015 Concerning the Grand Design of APIP Capability Improvement in the Inspectorate of Aceh Tamiang Regency based on Edward III's theory, it has been going well but not yet maximally implemented.

Keywords: Regency Inspectorate, Supervision, Implementation, Policy, Capability.
\end{abstract}

How to Cite: Hakim M, Kusmanto H, Isnaini. (2020). Implementasi Kebijakan Peraturan Kepala Badan Pengawasan Keuangan dan Pembangunan Republik Indonesia Nomor 6 Tahun 2015. Strukturasi: Jurnal Ilmiah Magister Administrasi Publik, 1(2) 2020: 131-137,

*E-mail: muhammadhakim1980@gmail.com 


\section{PENDAHULUAN}

Perubahan paradigma penyelenggaraan pemerintahan daerah (otonomi daerah) di Indonesia dari pola sentralisasi menjadi desentralisasi memiliki konsekuensi ter- hadap makin besarnya penyerahan we- wenang dari pemerintah pusat ke pemerintah daerah sehingga pemerintah daerah memiliki kewenangan yang cukup besar untuk mengatur dan mengurus rumah tangganya sendiri secara otonom. Otonomi daerah dengan asas desentralisasi memberi kewenangan dan kesempatan yang luas kepada pemerintah daerah untuk menyelenggarakan pemerintahan secara langsung dan bertanggungjawab dalam mewujudkan kesejahteraan masyarakat di daerah. Kewenangan yang luas membutuhkan pengawasan yang optimal, karena tanpa pengawasan yang optimal peluang terjadinya penyimpangan dan penyalahgunaan kewenangan akan se- makin besar sehingga akan mengakibatkan kerugian keuangan negara, dan meng- hambat terwujudnya kesejahteraan masyarakat.

Peraturan Pemerintah Nomor 79 Tahun 2005 tentang Pedoman Pembinaan dan Pengawasan Penyelenggaraan Pe- merintahan Daerah, pasal 12 menyebutkan bahwa pengawasan terhadap urusan pemerintahan di daerah dilaksanakan oleh Aparat Pengawasan Intern Pemerintah (APIP) sesuai dengan fungsi dan kewenangannya. Perwujudan peran APIP yang efektif didalam pasal 11 Peraturan Pemerintah Nomor 60 Tahun 2008 sekurang-kurangnya harus memberikan keyakinan yang memadai atas ketaatan, kehematan, efisiensi, dan efektivitas pencapaian tujuan penyelenggaraan tugas dan fungsi Instansi Pemerintah; memberikan peringatan dini dan meningkatkan efektivitas manajemen risiko dalam penyelenggaraan tugas dan fungsi Instansi Pemerintah; dan memelihara dan meningkatkan kualitas tata kelola penyelenggaraan tugas dan fungsi Instansi Pemerintah.

Dalam rangka mewujudkan peran APIP yang efektif sesuai PP 60 Tahun 2008, BPKP selaku instansi pembina Jabatan Fungsional Auditor (JFA) di lingkungan APIP mengeluarkan Peraturan Kepala Badan Pengawasan Keuangan Dan Pembangunan Rebuplik Indonesia Nomor 6 Tahun 2015 Tentang Grand Design Peningkatan Kapabilitas Aparat Pengawasan Intern Pemerintah. Pengertian dari Kapabilitas APIP yaitu kemampuan untuk melaksanakan tugas-tugas pen- gawasan yang terdiri dari unsur yang saling terkait yaitu kapasitas, kewenangan dan kompetensi SDM APIP yang harus dimiliki, juga merupakan upaya memperkuat, meningkatkan, mengembangkan kelembagaan, tata laksana, manajemen sumber daya manusia agar dapat melaksanakan peran dan fungsi APIP secara efektif. Sejak dikeluarkan Peraturan Keputusan Kepala Badan Pengawasan Keuangan dan Pembangunan (BPKP) Republik Indonesia semua instansi pemerintah (Inspektorat Kabupaten) dituntut untuk mampu menghasilkan kinerja instansinya secara baik dan Peningkatan Profesional Pemeriksa yang handal (Pasi, Abdul \& Isnaini, 2016).

Dari latar belakang masalah yang telah diuraikan, maka penelitian ini akan menganalisis implementasi Peraturan Kepala Badan Pengawasan Keuangan Dan Pembangunan Rebuplik Indonesia Nomor 6 Tahun 2015 Tentang Grand Design Peningkatan Kapabilitas Aparat Pengawasan Intern Pemerintah di Inspektorat Kabupaten Aceh Tamiang, yang akan peneliti telusuri dari kacamata Model Implementasi 
Kebijakan Goerge C. Edward III, yang dapat membantu menguraikan implementasi kebijakan Kapabilitas Aparat Pemeriksa Intern Pemerintah di Inspektorat Kabupaten Aceh Tamiang.

\section{METODE PENELITIAN}

Tujuan penelitian ini adalah untuk mengetahui dan menggambarkan mengenai Implementasi Peraturan Kepala Badan Pengawasan Keuangan Dan Pembangunan Rebuplik Indonesia Nomor 6 Tahun 2015 Tentang Grand Design Peningkatan Kapabilitas Aparat Pen- gawasan Intern Pemerintah di Inspektorat Kabupaten Aceh Tamiang dan menganalisis faktor-faktor yang dapat mengatasi kendala dalam implementaasi Peraturan Kepala Badan Pengawasan Keuangan Dan Pembangunan Rebuplik Indonesia Nomor 6 Tahun 2015 Tentang Grand Design Peningkatan Kapabilitas Aparat Pengawasan Intern Pemerintah di Inspektorat Kabupaten Aceh Tamiang, dengan demikian penelitian ini merupakan penelitian Deskriptif dengan mengambarkan keadaan subjek obyek penelitian pada saat sekarang berdasarkan fakta yang tampak. Data yang diperlukan dalam penelitian ini meliputi data primer dan data sekunder.

Teknik pengumpulan data primer yang pada umumnya digunakan dalam penelitian kualitatif meliputi, wawancara, observasi dan dokumentasi. Data primer merupakan data yang diperoleh langsung oleh peneliti melalui wawancara dan observasi dilapangan. Sementara data sekunder merupakan data yang diperoleh dari literatur atau dokumen (Sugiyono, 2014). Sumber data yang digunakan dalam penelitian ini adalah sumber data primer, yaitu data yang diperoleh langsung oleh peneliti dari lapangan. Creswell (2013) menyebutkan bahwa peneliti dapat menggunakan observasi, wawancara, dan dokumentasi.

Teknik analisis data yang digunakan adalah teknik analisa deskriptif, dimana datadata dalam bentuk kualitatif khususnya dari wawancara. Secara induktif peneliti akan mencoba mengolah data yang bersifat kualitatif untuk menarik kesimpulan tentang bagaimana Implementasi Peraturan Kepala Badan Pengawasan Keuangan Dan Pembangunan Rebuplik Indonesia Nomor 6 Tahun 2015 Tentang Grand Design Peningkatan Kapabilitas Aparat Pengawasan Intern Pemerintah berdasarkan teori Implementasi menurut Edward III yang dipengaruhi oleh empat variabel, yakni komunikasi, sumber daya, disposisi/kecenderungan atau tingkah laku dan struktur birokrasi (Budi Winarno, 2002)

Reduksi Data, yakni data dengan diperoleh dilokasi penelitian (data lapangan) dituangkan dalam uraian atau laporan yang lengkap dan terinci. Laporan dari lapangan akan direduksi, dirangkum, dipilih hal-hal yang pokok, difokuskan pada hal-hal yang penting kemudian dicari tema atau polanya. Reduksi data berlangsung secara terus menerus selama proses penelitian berlangsung. Selama pengumpulan data berlangsung. Terjadilah tahapan reduksi data.

Sajian data yakni memudahkan bagi peneliti untuk melihat gambaran secara keseluruhan atau bagian-bagian tertentu dari penelitian. Data yang disajikan adalah 
ringkasan data primer (hasil wawancara) dan data sekunder (dokumen-dokumen) dalam bentuk tabel maupun deskripsi.

Penarikan kesimpulan, yakni sejak awal memasuki lokasi penelitian dan selama proses pengumpulan data. Peneliti berusaha untuk menganalisa data, yang dikumpulan dengan cara mencari tema dari hal-hal sering timbul, dimana persamaan yang sering muncul, antara lain "kesulitan teknis, koordinasi, dan kualitas SDM." Akan tetapi dengan bertambahnya data melalui proses verifikasi secara terus menerus, maka diperoleh kesimpulan, dengan kata lain setiap kesimpulan senantiasa terus dilakukan verifikasi selama penelitian berlangsung, adapun data yang sering memerlukan verifikasi antara lain data yang terkait dengan kesulitan teknis dan data kualitas SDM.

Dalam menentukan informan dalam penelitian ini adalah orang-orang yang dianggap memiliki informasi kunci (key informan) yang dibutuhkan di lokasi penelitian berdasarkan kebutuhan data yang ada, maka penulis menentukan yang menjadi key informan dalam penelitian ini

\section{HASIL DAN PEMBAHASAN}

Komunikasi, proses komunikasi dalam pelaksanaan kebijakan Peraturan Kepala Badan Pengawasan Keuangan Dan Pembangunan Rebuplik Indonesia Nomor 6 Tahun 2015 Tentang Grand Design Peningkatan Kapabilitas Aparat Pengawasan Intern Pemerintah di Inspektorat Kabupaten Aceh Tamiang, berdasarkan mekanisme yang ditetapkan terdiri dari transmission (penyampaian Informasi), clarity (kejelasan), dan consistency (konsisten). Mekanisme yang digunakan dalam komunikasi jika diterapkan dengan baik pada implementasi kebijakan Peraturan Kepala Badan Pengawasan Keuangan Dan Pembangunan Rebuplik Indonesia Nomor 6 Tahun 2015 Tentang Grand Design Peningkatan Kapabilitas Aparat Pengawasan Intern Pemerintah di Inspektorat Kabupaten Aceh Tamiang akan membawa perubahan pada pelaksanaan kebijakan peraturan ini (Pasi, et .all, 2016).

Berdasarkan dari penjelasan ketiga indicator yang mempengaruhi variabel komunikasi yaitu transmission (penyampaian Informasi) clarity (kejelasan), dan consistency (konsisten) bahwa komunikasi dalam implementasi kebijakan Peraturan Kepala Badan Pengawasan Keuangan Dan Pembangunan Rebuplik Indonesia Nomor 6 Tahun 2015 Tentang Grand Design Peningkatan Kapabilitas Aparat Pengawasan Intern Pemerintah ini sudah berjalan cukup baik (Saputra, et .all,2016).

Sumber Daya, berdasarkan penjelasan dari indikator-indikator tersebut mengenai sumber daya manusia baik kuantitas dan kualitas, informasi, kewenangan dan fasilitas belum cukup optimal dalam menunjang berjalannya Implementasi kebijakan Peraturan ini. Hal ini disebabkan oleh masih kurangnya sumber daya manusia berdasarkan kuantitas maupun kualitas masih kurang. Dari segi Kuntitas yaitu kurang nya jumlah Auditor dan P2UPD dan dari segi kualitas yaitu kurang memiliki keahlian, pengetahuan, ketrampilan, dan kemampuan dalam melaksanakan tugas atau pekerjaannya. Kemudian dari segi sumber daya anggaran untuk menunjang Peningkatan Kapabilitas APIP ini juga masih sangat Minim. 
Sikap atau DisposisI, berdasarkan Penelitian ini, dari dua indikator yaitu Komitmen aparatur birokrasi/Pengangkatan Birokrasi dan insentif dapat ditarik kesimpulan bahwa komitmen birokrasi dan insentif sudah berjalan optimal.

Struktur BirokrasI, kedua indikator tersebut baik SOP maupun Fragmentasi maka dapat ditarik kesimpulan bahwa struktrur birokrasi dalam Implementasi kebijakan peraturan ini belum berjalan optimal (Pinayungan, et .all, 2018). Hal ini dikarenakan belum ada SOP untuk mendukung Pelaksanaan Kebijakan tersebut, karena dengan tidak adanya SOP yang mendukung berdampak pada tidak optimalnya Implementasi kebijakan peraturan tersebut. Jadi setelah penjelasan empat variabel meliputi komunikasi, sumber daya, disposisi dan struktur birokrasi dalam pelaksanaan/implementasi kebijakan Peraturan ini dapat disimpulkan bahwa implementasi belum berjalan secara optimal. Hal ini disebabkan oleh: Pertama, dari segi sumber daya yaitu: disebabkan oleh masih kurangnya sumber daya manusia berdasarkan kuantitas maupun kualitas masih kurang. Dari segi Kuntitas yaitu kurang nya jumlah Auditor dan P2UPD dan dari segi kualitas yaitu kurang memiliki keahlian, pengetahuan, ketrampilan, dan kemampuan dalam melaksanakan tugas atau pekerjaannya. Kemudian dari segi sumber daya anggaran untuk menunjang Peningkatan Kapabilitas APIP ini juga masih sangat Minim. Kedua, dari segi Struktur Birokrasi yaitu belum ada SOP untuk mendukung pelaksanaan kebijakan tersebut.

Sedangkanpelaksanaan/implementasi kebijakan Peraturan ini yang telah berjalan optimal yaitu: Pertama, dari segi komunikasi dan Kedua, dari segi Sikap atau Disposisi. Jadi dapat disimpulkan bahwa implementasi kebijakan Peraturan Kepala Badan Pengawasan Keuangan Dan Pembangunan Rebuplik Indonesia Nomor 6 Tahun 2015 Tentang Grand Design Peningkatan Kapabilitas Aparat Pengawasan Intern Pemerintah di Inspektorat Kabupaten Aceh Tamiang sudah berjalan dengan baik (Sinulingga, et .all, 2018).

\section{Faktor Penghambat}

Adapun faktor yang menjadi hambatan Implementasi Kebijakan Peraturan Kepala Badan Pengawasan Keuangan Dan Pembangunan Rebuplik Indonesia Nomor 6 Tahun 2015 Tentang Grand Design Peningkatan Kapabilitas Aparat Pengawasan Intern Pemerintah di Inspektorat Kabupaten Aceh Tamiang antara lain: 1) kurangnya sumber daya manusia berdasarkan kuantitas yaitu kurang nya jumlah Auditor dan P2UPD; 2) kurangnya sumber daya manusia berdasarkan kualitas yaitu kurang memiliki keahlian, pengetahuan, ketrampilan, dan kemampuan dalam melaksanakan tugas atau pekerjaannya; 3) segi sumber daya anggaran untuk menunjang Peningkatan Kapabilitas APIP ini juga masih sangat Minim; 4) belum ada SOP untuk mendukung Pelaksanaan Kebijakan tersebut.

\section{SIMPULAN}

Implementasi Peraturan Kepala Badan Pengawasan Keuangan Dan Pembangunan Rebuplik Indonesia Nomor 6 Tahun 2015 Tentang Grand Design Peningkatan Kapabilitas Aparat Pengawasan Intern Pemerintah di Inspektorat Kabupaten Aceh 
Tamiang berdasarkan teori Edward III yang meliputi 4 variabel antara lain komunikasi, sumberdaya, disposisi, dan struktur birokrasi sebagai berikut: Komunikasi dalam implementasi kebijakan Peraturan Kepala Badan Pengawasan Keuangan Dan Pembangunan Rebuplik Indonesia Nomor 6 Tahun 2015 Tentang Grand Design Peningkatan Kapabilitas Aparat Pengawasan Intern Pemerintah di Inspektorat Kabupaten Aceh Tamiang ini sudah berjalan cukup baik. Sumber daya dalam implementasi kebijakan Peraturan Kepala Badan Pengawasan Keuangan Dan Pembangunan Rebuplik Indonesia Nomor 6 Tahun 2015 Tentang Grand Design Peningkatan Kapabilitas Aparat Pengawasan Intern Pemerintah di Inspektorat Kabupaten Aceh Tamiang ini belum berjalan dengan baik disebabkan oleh masih kurangnya sumber daya manusia berdasarkan kuantitas maupun kualitas masih kurang. Dari segi Kuntitas yaitu kurang nya jumlah Auditor dan P2UPD dan dari segi kualitas yaitu kurang memiliki keahlian, pengetahuan, ketrampilan, dan kemampuan dalam melaksanakan tugas atau pekerjaannya. Kemudian dari segi sumber daya anggaran untuk menunjang Peningkatan Kapabilitas APIP ini juga masih sangat Minim.

Disposisi dalam implementasi kebijakan Peraturan Kepala Badan Pengawasan Keuangan Dan Pembangunan Rebuplik Indonesia Nomor 6 Tahun 2015 Tentang Grand Design Peningkatan Kapabilitas Aparat Pengawasan Intern Pemerintah di Inspektorat Kabupaten Aceh Tamiang ini sudah berjalan cukup baik. Sruktur Birokrasi dalam implementasi kebijakan Peraturan Kepala Badan Pengawasan Keuangan Dan Pembangunan Rebuplik Indonesia Nomor 6 Tahun 2015 Tentang Grand Design Peningkatan Kapabilitas Aparat Pengawasan Intern Pemerintah di Inspektorat Kabupaten Aceh Tamiang ini belum berjalan dengan baik disebabkan oleh belum ada SOP untuk mendukung Pelaksanaan Kebijakan tersebut.

\section{DAFTAR PUSTAKA}

Agustino, L. (2008). Dasar-dasar Kebijakan Publik. Bandung: Alfa Beta.

Andersen, E.J. (1997). Public Policy-Making. New York: Holt.

Arifin, A. (2011). Administrasi Pemerintahan Dalam Pembangunan. Jakarta: CV. Haji Mas Agung.

Creswell, J. W. (2013). Research Design: Pendekatan Kualitatif, Kuantitatif, dan Mixed. Yogyakarta: Pustaka Pelajar.

Dunn, N., William, 1994, Public Policy Analysis: An Introduction. Edisi Ke-2,

Edison, E., Anwar Y \& Komariah, J. (2016). Manajemen Sumber daya Manusia, Strategi dan Perubahan dalam rangka meningkatkan kinerja pegawai dan Organisasi. Bandung: Alfabeta.

Edward, G.C. III. (1980). "Implementing Public Policy". Washington DC: Congresional, Quartely Press.

Engelwood Cliffs, NJ. Prentice Hall. Yogyakarta: Gadjah Mada University Press.

Figy Lumempow, Inggriani Elim \& I Gede Suwetja. (2017) “Evaluasi Kinerja Pengawasan Pengelolaan Keuangan Daerah Diukur Dari Peraturan Bpkp no. 16 tahun 2015 pada Inspektorat Kabupaten Minahasa Selatan. Jurnal Riset Akuntansi Going Concern 12(2), 2017, 1179-1188.

Halim, Abdul \& Muhammad S. Kusufi. (2012). Akuntansi Sektor Publik Akuntansi Keuangan Daerah. Jakarta: Erlangga.

Isamy, M. Irfan. (1994). Prinsip-prinsip Perumusan Kebijakan Negara. Jakarta: Bumi Aksa.

Ismail, dkk. (2008). Implementation of Audit Quality Control System: Preliminary Evidence From Small And Medium Audit Practices In Malaysia. Universiti Teknologi MARA Faculty of Accountancy Shah Alam, Malaysia. The 9th Asian Academic Accounting Association Annual Conference Dubai, United Arab Emirates.

Karianga, H. (2011). Partisipasi Masyarakat Dalam Pengelolaan Keuangan Daerah. Bandung: PT Alumni Mahmudi. (2015). Manajemen Kinerja Sektor Publik. Yogyakarta: UUP STIM YKPN.

Mulyadi, Dedy. (2016). Studi Kebijakan Publik dan Pelayanan Publik. Bandung: Alfabeta. 
Nugroho, R. (2012). Public Policy For The Developing Countries. Yogyakarta: Pustaka Pelajar.

Nugroho, R. (2012). Public Policy: Dinamika Kebijakan, Analisis Kebijakan, Manajemen Kebijakan. Jakarta: Elex Media Komputindo.

Pasi, N., Abdul K., Isnaini, (2016), Implementasi Sistem Informasi Manajemen Daerah Keuangan Berbasis Akrual pada Pemerintah Kebupaten Dairi, Jurnal Administrasi Publik (Public Admnistration Journal), 7 (1): 49-63

Santosa, H., DG. Hidyata \& P. Indrayono. (2003). "Program Penanggulangan Kemiskinan Bersasaran di Daerah Istimewa Yogjakarta". Jurnal Ekonomi

Sedarmayanti. (2011). Membangun dan Mengembangkan Kepemimpinan Serta Meningkatkan Kinerja Untuk Meraih Keberhasilan. Bandung: PT. Refika Aditama.

Sedarmayanti. (2016). Manajemen Sumber Daya Manusia, Reformasi Birokrasi dan Manajemen Pengawai Negeri Sipil. Bandung: PT. Refika Aditama.

Soenarko, H. (2003) Public Policy. Surabaya: Airlangga University.

Subarsono. (2005). Analisis Kebijakan Publik. Yogyakarta: Pustaka Pelajar.

Subarsono. (2006). Analisa Kebijakan Publik: Konsep, Teori, dan Aplikasi. Yogyakarta: Pustaka Pelajar.

Sugiyono $_{2}$ (2008). Metode Penelitian Administrasi. Bandung: Alfabeta.

Sugiyono. (2010). Metode Penelitian Kuantitatif dan Kualitatif $R$ \& D. Bandung: Alfabeta.

Suwanda, D. \& Dailibas. (2016). Panduan Penerapan Sistem Pengendalian Intern Pemerintah. Jakarta : PPM.

Tangkilisan, H.N.S. (2003). Implementasi Kebijakan Publik. Jakarta: Lukman Offset.

Tangkilisan, H.N.S. (2003). Kebijakan Publik Yang Membumi. Jakarta: Lukman Offset.

Toding, D.S. (2016). “Kapasitas Aparat Inspektorat Dalam Pengawasan Keuangan Daerah Kabupaten Sidoarjo (Kajian Terhadap Kompetensi Aparat Inspektorat di Kabupaten Sidoarjo)". Jurnal Ilmiah Administrasi Publik, 2 (1): 11-18

Wahab, S.A. (2008). Analisis Kebijakan Publik. Malang: Universitas Muhamadiyah.

Wibawa, S. (1994). Evaluasi Kebijakan Publik. Jakarta, PT. Grafindo Persada.

Wibowo. (2013). Perilaku Dalam Organisasi. Jakarta: PT. Raja Grafindo Persada.

Widodo, J. (2009). Analisis Kebijakan Publik: Konsep dan Aplikasi Analisis Proses Kebijakan Publik. Malang: Bayumedia Publishing.

Winarno, B. (2005). Teori \& Proses Kebijakan Publik. Yogyakarta: Media Pressindo.

Yin, R.K. (2009). Case Study Research: Design and Methods-Applied Sosial Research Methods Series. London: Sage.

Saputra, A., Kusmanto, H. \& Turnip, K. (2016), Implementasi Keputusan Menteri Pendidikan Dan Kebudayaan Republik Indonesia Tentang dalam Pembinaan Organisasi Kemahasiswaan, Jurnal Administrasi Publik, 6 (1): 1 - 12

Pasi, N., Kadir, A. \& Isnaini, (2016), Implementasi Sistem Informasi Manajemen Daerah Keuangan Berbasis Akrual pada Pemerintah Kebupaten Dairi, Jurnal Administrasi Publik : Public Administration Journal : Public Admnistration Journal, 7 (1): 49-63

Pinayungan, J. Kusmanto, H. \& Isnaini. (2018). Implementasi Peraturan Menteri Perhubungan Republik Indonesia Tentang Standar Keselamatan Lalu Lintas Dan Angkutan Jalan. Jurnal Administrasi Publik : Public Administration Journal : Public Admnistration Journal. 8 (1): 108-123.

Sinulingga, L.O. Nasution, M.H.T. \& Batubara, B.M. (2018). Implementasi Kebijakan Pajak Progresif Bagi Kendaraan Bermotor. PERSPEKTIF, 7 (1): 19-23

Peraturan Kepala Badan Pengawasan Keuangan dan Pembangunan Nomor PER-1633/K/JF/2011 Tentang Pedoman Teknis Peningkatan Kapabilitas Aparat Pengawasan Intern Pemerintah.

Peraturan Kepala Badan Pengawasan Keuangan dan Pembangunan Nomor No. 16 Tahun 2015 Pedoman Teknis Peningkatan Kapabilitas APIP.

Peraturan Kepala Badan Pengawasan Keuangan dan Pembangunan Nomor 6 Tahun 2015 Tentang Grand Design Peningkatan Kapabilitas Aparat Pengawasan Intern Pemerintah Tahun 2015-2019.

Peraturan Pemerintah No. 60 Tahun 2008 Tentang Sistem Pengendalian Intern Pemerintah.

Peraturan Pemerintah Nomor 79 Tahun 2005 Tentang Pedoman Pembinaan dan Pengawasan Penyelenggaraan Pemerintahan Daerah.

Peraturan Pemerintah Nomor 60 Tahun 2008 Tentang Sistem Pengendalian Intern Pemerintah.

Peraturan Presiden Nomor 81 Tahun 2010 Tentang Grand Design Reformasi Birokrasi 2010-2025.

www.acehtamiangkab.go.id/selavang-pandang/seiarah-aceh-tamiang.html

Rakyat, Artikel Tahun II No.2 April 2002, Jakarta, www.ekonomirakyat.org 